\title{
Screening for abdominal aortic aneurysm (AAA) reduced AAA mortality in Danish men 64-73 years of age
}

Lindholt JS, Juul S, Fasting $\mathrm{H}$, et al. Screening for abdominal aortic aneurysms: single centre randomised controlled trial. BMJ 2005;330:750.

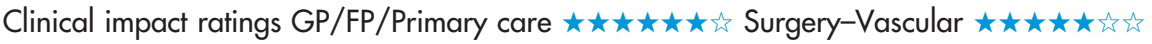

In Danish men 64-73 years of age, does screening for abdominal aortic aneurysm (AAA) reduce specific mortality caused by AAA and all cause morality?

\section{METHODS}

$-$

Design: randomised controlled trial.

?

Allocation: unclear allocation concealment. *

Blinding: blinded (outcome assessors).*

Follow up period: mean 52 months.

Setting: 5 hospitals in Viborg County, Denmark

을 Participants: 12639 Danish men 64-73 years of age (mean age 68 y) born between 1921 and 1933 who were living in Viborg County, Denmark.

D Intervention: screening for AAA by abdominal ultrasonography $(n=6333$ ) or no screening (control group, $n=6306)$. An AAA was deemed to be present if the infrarenal aortic diameter was $\geqslant 3 \mathrm{~cm}$. Participants with $A A A \geqslant 5 \mathrm{~cm}$ were referred for surgical evaluation, and those with smaller aneurysms were offered annual scans to check for expansion.

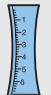

Outcomes: specific mortality caused by AAA, all cause mortality, number of planned and emergency operations for AAA, number of ruptured AAAs, and number of life years gained.

Patient follow up: all participants were included in the intention to screen analyses.

*See glossary.
MAIN RESULTS

The rates of specific mortality caused by AAA, emergency operations for AAA, and ruptured AAA were lower in the screened group than in the control group (table). However, the rates of all operations combined and of planned elective operations were greater in the screened group than in the control group (table). The groups did not differ for all cause mortality (table). The number of life years gained by offering screening to 6333 men was 32 (95\% CI 14 to 49 ) during the first 5 years, and might be expected to increase with time.

\section{CONCLUSION}

In Danish men 64-73 years of age, screening for abdominal aortic aneurysm (AAA) reduced specific mortality caused by AAA but not all cause morality.

Abstract and commentary also appear in ACP Journal Club.

he study by Lindholt et al is 1 of several large population screening
studies and it confirms previous findings, particularly those of the
MASS trial, ${ }^{2}$ that screening for AAA reduces specific mortality
caused by AAA. In men $64-73$ years of age, about 3 AAA related deaths
were averted for every 1000 men invited for screening. However, the
$75 \%$ reduction in emergency surgery among the screened population was
offset by a $3-4$ fold increase in the total number of aneurysm procedures.
Because the cost effectiveness of screening is highly dependent on the
underlying prevalence, screening a population with a low level of
opportunistic identification of AAA and high prevalence will be most cost
effective.
Clearly, screening is effective in a population of men $64-73$ years of
age. But what are the most cost effective screening strategies,
mechanisms for achieving a high rate of compliance, cost effectiveness
in other populations, relative merits of different screening regimens, and
effects of new operations of endovascular aneurysm repair in managing
a screened population? Answers to such questions are likely to require a
combination of research methods, including further clinical trials and the
use of decision and economic modelling techniques. ${ }^{3}$
Jonathan A Michaels, MA, MChir, FRCS
University of Sheffield, Sheffield, UK
1 Fleming C, Whitlock EP, Beil TL, et al. Ann Intern Med 2005;142:203-11.
2 Ashton HA, Buxton MJ, Day NE, et al. Lancet 2002;360:1531-9.
3 Wanhainen A, Lundkvist J, Bergqvist D, et al. J Vasc Surg 2005;41:741-
51 .

For correspondence: Dr J S Lindholt, Vascular Research Unit, Viborg, Denmark. jes.s.lindholı@sygehusviborg.dk

Sources of funding: Health department of Viborg County; Danish Heart Foundation; Danish National Council of Health Research; Foundation of Research in Western Denmark; Foundation of Rosa and Asta Jensen.

Screening for abdominal aortic aneurysm (AAA) $v$ no screening (control) in Danish men 64-73 years of age*

\begin{tabular}{|c|c|c|c|c|}
\hline Outcomes at mean 52 months & Screening & Control & $\operatorname{RRR}(95 \% \mathrm{Cl})$ & NNT (Cl) \\
\hline $\begin{array}{l}\text { Specific mortality caused by AAA } \\
\text { All cause mortality } \\
\text { Ruptured aneurysms } \\
\text { Emergency operations for AAA }\end{array}$ & $\begin{array}{l}0.14 \% \\
14.8 \% \\
0.13 \% \\
0.08 \%\end{array}$ & $\begin{array}{c}0.43 \% \\
16.2 \% \\
0.46 \% \\
0.32 \%\end{array}$ & $\begin{array}{l}67 \%(29 \text { to } 84) \\
8 \%(0 \text { to } 15) \\
73 \%(40 \text { to } 87) \\
75 \%(34 \text { to } 91)\end{array}$ & $\begin{array}{l}350 \text { (203 to } 994) \\
\text { Not significant } \\
300 \text { (184 to } 652) \\
420(239 \text { to } 1103)\end{array}$ \\
\hline & & & RRI (CI) & $\mathrm{NNH}(\mathrm{Cl})$ \\
\hline $\begin{array}{l}\text { Planned elective operations } \\
\text { All operations combined }\end{array}$ & $\begin{array}{l}0.76 \% \\
0.84 \%\end{array}$ & $\begin{array}{l}0.17 \% \\
0.49 \%\end{array}$ & $\begin{array}{l}335 \%(126 \text { to } 736) \\
70 \%(9 \text { to } 165)\end{array}$ & $\begin{array}{l}172(119 \text { to } 279) \\
290(156 \text { to } 1578)\end{array}$ \\
\hline
\end{tabular}

*Abbreviations defined in glossary; RRR, RRI, NNT, NNH, and Cl calculated from data in article. 